
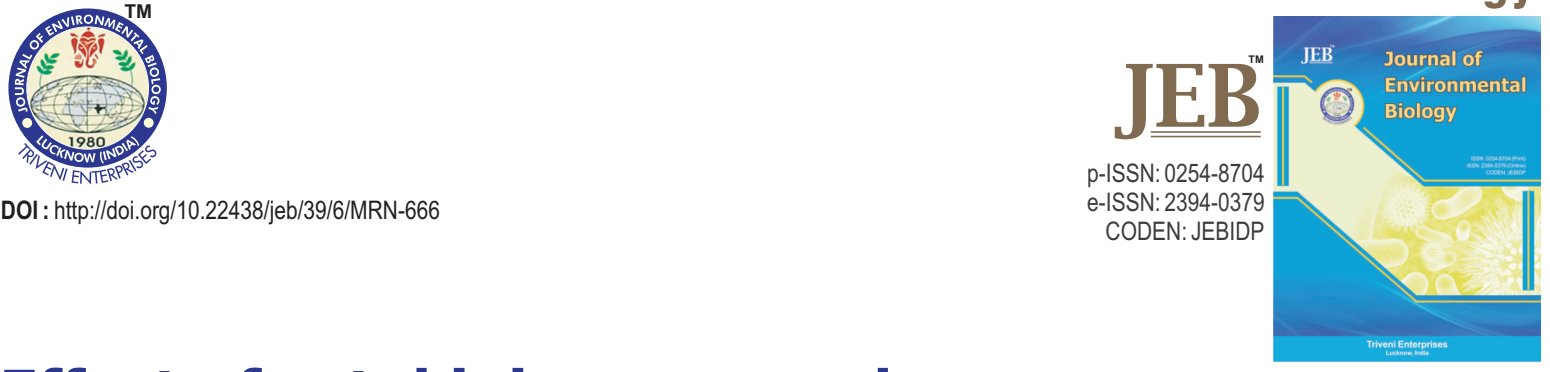

\title{
Effect of cytokinins on membrane stability and cell viability of wheat crop under PEG-induced drought condition
}

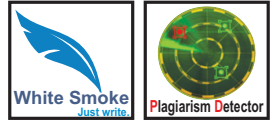

Authors Info

A. Kaur* and S.K. Thind

Department of Botany, Punjab Agricultural University, Ludhiana-141 001, India

*Corresponding Author Email : aparjotranu@gmail.com

Key words

Cell viability

Cytokinins

Drought stress

Membrane stability

Polyethylene glycol

Publication Info

Paper received : 10.06 .2017

Revised received : 29.09.2017

Re-revised received: 02.12 .2017

Accepted: 22.04 .2018

\section{Abstract}

Aim : The present study was carried out to examine the impact of foliar application of cytokinins [Kinetin (Kn) and Benzyl adenine (BA)] on membrane stability and cell viability of wheat seedlings, and their ability to sustain vigour and growth rate under physiological drought stress.

Methodology : Twenty seeds were surface sterilized with $0.1 \% \mathrm{HgCl}$, and sown in each Petriplate using distilled water. On $3^{\text {rd }}$ day, seedlings were shifted to Pertri-plates supplemented with PEG-6000 (-0.4Mpa) solution to induce drought stress. On $5^{\text {th }}$ day, foliar application of different $\mathrm{Kn}$ and $\mathrm{BA}$ concentration were given and data was recorded on 7 days after sowing for calculating the membrane thermal stability (MTS), to determine cell viability by Tetrazolium chloride test (TTC), relative growth rate (RGR). For vigour index (VI), seeds were directly sown in PEG supplemented Petri-plates. Germination per cent and epicotyl length were calculated following $\mathrm{Kn}$ and $\mathrm{BA}$ treatments on same day, except control.

Results : Polyethylene glycol (PEG) induced water deficit had significant $(p \leq 0.05)$ negative effect on both MTS and cell viability of wheat seedlings. There was $27.04 \%$ more reduction of MTS in PBW660 over control. In the experiment, both $\mathrm{Kn}$ and BA increased MTS significantly in all the wheat genotypes. Application of Kn @ 40 ppm showed maximum MTS in HD2967 (94.6). With that application per cent increase was recorded more in PBW660 (25.47\%). PEG induced drought reduced cell viability in all genotypes. In contrast, $\mathrm{Kn}$ and BA increased the viability of cells significantly $(p \leq$
PEG induced drought stress at seeding stage

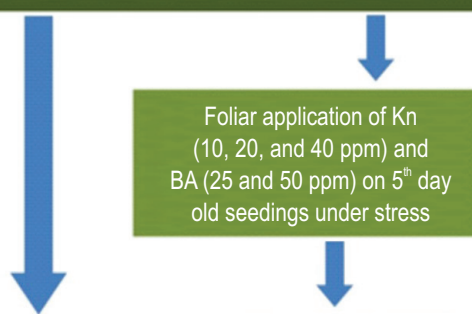

From 7 day old seedings

membrane stability, cell

viability, RGR and Vigou

Index was estimated

From 7 day old seedings

membrane stability, cell

viability, RGR and Vigour

Index was estimated
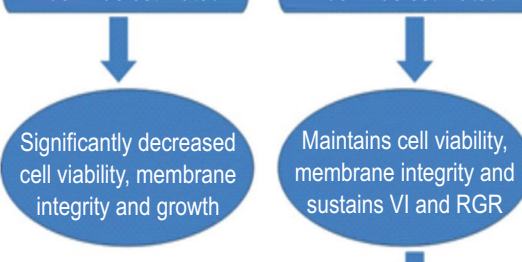

Maintains cell viability,

membrane integrity and

sustains VI and RGR

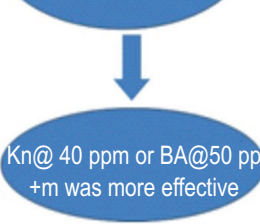
0.05). Among the treatments, Kn @ 40 ppm promoted more physiological effect on all genotypes. PEG induced drought stress reduced maximum RGR in PBW658 by $35.29 \%$, and VI in PBW660 by $28.62 \%$ as compared to control. Although higher the concentration of cytokinins, more was the positive effect, but Kn @ 40 ppm promoted more effect as compared to other concentrations of Kn and BAon seedling growth.

Interpretation : Kn and BA may be used in foliar mode to ameliorate the negative effects of water deficit stress on growth by sustaining membrane integrity and viability of cells of wheat seedlings. 


\section{Introduction}

Wheat is the most widely cultivated crops in the world. It occupies more than 220 million hectares of crop land producing 715 million tonnes of food grains with an efficiency of $3.2 \mathrm{t}$ ha (FAO, 2015). It is estimated that 65 million ha of wheat growing area is affected by drought (FAO, 2013). Crop water deficit emerges from both inadequate rainfall and depletion of soil water potential during the growing season which is a limiting factor for sustaining high crop yield (Vadez et al., 2011; 2012). Projections show an increase in intense rain events, and diminution in the number of rain days that leads to increased risk of drought (Vadez et al., 2011). Kulkarni and Deshpande (2007) showed that Polyethylene glycol (PEG) molecules are non-reactive, no-ionic and virtually impermeable to cell membranes. It can persuade invariable water stress without causing direct interference to physiological processes.

Water stress causes water loss from plant tissues which seriously impair both membrane structure and function (Buchanan et al., 2000). Cell membrane is one of the first targets of plant stress, and it determines the ability of plants to maintain membrane integrity or stability under drought. Germination of seeds and growth of seedlings characters are extremely important factors in determining yield (Rauf et al., 2007). Seed vigour index and shoot length are the most sensitive to drought stress, followed by root length and coleoptiles length. The rate of seed germination and the final germination percentage as well as the amount of water absorbed by the seeds are lowered considerably with the rise of osmotic stress level. Yang et al. (2002) physiological damage caused by water stress and stress signaling are closely associated with the endogenous level and balance of hormones. Cytokinin synthesis and transport are typically prohibited whereas degradation is promoted under water stress, which have been associated with growth in hibition and reduction instress tolerance of plant. The role of cytokinins in delaying leaf senescence has been shown by the exogenous application of cytokinins (Okamoto et al., 2010) and by promoting endogenous production of cytokinin through transgenic modification of cytokinin biosynthesis genes or genes regulating cytokinin degradation pathways. Therefore, the present study was carried out to evaluate the role of foliar application of cytokinins on membrane thermal stability, cell viability, relative growth rate and vigour index in four wheat genotypes under PEG induced drought stress at seedling stage.

\section{Materials and Methods}

Four wheat genotypes (WH1105, HD2967, PBW658 and PBW660) were obtained from the Department of Plant Breeding and Genetics and laboratory investigations were conducted in the Department of Botany, Punjab Agricultural University, Ludhiana. Prior to experiment, the seeds were surface sterilised using mercury chloride $(0.1 \%)$ for 2-3 min to protect healthy seeds from any fungal growth during the period of germination. The Petri plates were also sterilised by putting them into oven at $100^{\circ} \mathrm{C}$ for about $1 \mathrm{hr}$. Petri plates were lined with pre- autoclaved ordinary blotting paper in circular form in accordance with the size of Petriplate. Twenty seeds were then sown in each Petri-plate using distilled water, and incubated at room temperature of $25 \pm 2^{\circ} \mathrm{C}$, relative humidity 60 and light 12 hrs/day in an incubator. On $3^{\text {rd }}$ day, the seedlings were shifted to Petri plates supplemented with PEG (-0.4 Mpa) solution against control. On $5^{\text {th }}$ day, these seedlings were treated with the following treatments :

T1 - Distil water as control T2 - Stress (PEG-6000); T3Stress + Kn@10 ppm; T4 - Stress + Kn@ 20 ppm, T5 - Stress + Kn@ 40 ppm, T6 - Stress+BA@ 25 ppm and T7 -Stress+BA@ $50 \mathrm{ppm}$

Membrane thermal stability was calculated by the method given by Shanahan et al. (1990). Plant tissue was immersed in test tubes containing $20 \mathrm{ml}$ of de-ionized water stirred continuously at $28^{\circ} \mathrm{C}$. After $5 \mathrm{hrs}$, the electrolyte leakage was estimated by conductivity meter. The sample was then boiled for 30 min and conductivity was measured again.

Triphenyltetrazolium chloride reduction assay : This test was performed by the method of Towill and Mazur (1974). Two sets of two leaves $(3.5 \mathrm{~cm}$ each) per cultivar were excised and placed in a test tube with $0.1 \mathrm{ml}$ de-ionized water. One set was left at $25^{\circ} \mathrm{C}$ for $90 \mathrm{~min}$, and the other set was placed in a water bath at $49^{\circ} \mathrm{C}$ for 90 min. After that $10 \mathrm{ml}$ of TTC solution (0.8\% TTC in $0.05 \mathrm{M} \mathrm{NaPO}_{4}$

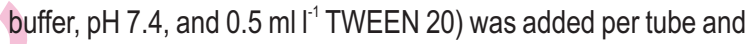
vacuum infiltrated for $10 \mathrm{~min}$. The tissue was incubated in TTC solution for $24 \mathrm{hrs}$ at $25^{\circ} \mathrm{C}$ in dark and placed individually in separate spectro-photometric tubes containing $2 \mathrm{ml}$ of $95 \%$ ethanol, and submerged for $24 \mathrm{hrs}$ at $25^{\circ} \mathrm{C}$ in the dark. Cell viability was determined by measuring the percentage reduction of TTC to formazan.

Relative Growth Rate (RGR) was calculated as suggested by Gardener et al. (1985) and Vigour Index (VI) by Abdul Baki and Anderson (1973).

Statistical analysis : The experimental data wasanalyzed by two way factor (genotype, treatment) under a completely randomised block design and analysis of variance (ANOVA) using software CPCS1 by Cochran and Cox (1967).

\section{Results and Discussion}

Measurement of solute leakage from the plant tissue was used to estimate the damage to the cell membrane caused by drought (Tardieu et al., 2012; Wang, 2016). The stability of membrane was observed more in control as compared with polyethylene gylcol treatment in all genotypes (Table 1). Polyethylene glycol induced stress significantly affected the stability of cell membranes of all genotypes. Genotype PBW660 followed by PBW658 had more adverse effects of polyethylene glycol caused water deficit on the stability of membrane. As membrane stability is recorded in terms of electrolyte leakage, the 
Table 1: Effect of different concentrations of kinetin (10,20 and $40 \mathrm{ppm}$ ) and benzyl adenine (25 and $50 \mathrm{ppm}$ ) on membrane thermal stability (MTS) at 7 DAS in wheat under PEG induced drought stress

\begin{tabular}{|c|c|c|c|c|c|}
\hline \multirow{2}{*}{$\begin{array}{l}\text { Treatments } \\
\text { Genotypes }\end{array}$} & \multicolumn{5}{|c|}{ Membrane thermal stability (\%) } \\
\hline & HD2967 & PBW660 & WH1105 & PBW658 & Mean \\
\hline T1 & 92.2 & 85.4 & 82.9 & 77.3 & 84.45 \\
\hline T2 & $\begin{array}{l}73.9 \\
(19.84 \downarrow)\end{array}$ & $\begin{array}{l}62.3 \\
(27.04 \downarrow)\end{array}$ & $\begin{array}{l}74.5 \\
(10.13 \downarrow)\end{array}$ & $\begin{array}{l}62.7 \\
(18.88 \downarrow)\end{array}$ & 68.35 \\
\hline $\mathrm{T} 3$ & $\begin{array}{l}81.9 \\
(9.76 \uparrow)\end{array}$ & $\begin{array}{l}68.9 \\
(9.57 \uparrow)\end{array}$ & $\begin{array}{l}80.9 \\
(7.91 \uparrow)\end{array}$ & $\begin{array}{l}69.3 \\
(9.52 \uparrow)\end{array}$ & 75.25 \\
\hline $\mathrm{T} 4$ & $\begin{array}{l}87.8 \\
(15.83 \uparrow)\end{array}$ & $\begin{array}{l}73.8 \\
(15.58 \uparrow)\end{array}$ & $\begin{array}{l}84.6 \\
(11.93 \uparrow)\end{array}$ & $\begin{array}{l}71.6 \\
(12.43 \uparrow)\end{array}$ & 79.45 \\
\hline T5 & $\begin{array}{l}94.6 \\
(21.88 \uparrow)\end{array}$ & $\begin{array}{l}83.6 \\
(25.47 \uparrow)\end{array}$ & $\begin{array}{l}89.7 \\
(16.94 \uparrow)\end{array}$ & $\begin{array}{l}77.3 \\
(18.88 \uparrow)\end{array}$ & 86.30 \\
\hline T6 & $\begin{array}{l}79.9 \\
(7.50 \uparrow)\end{array}$ & $\begin{array}{l}70.2 \\
(11.25 \uparrow)\end{array}$ & $\begin{array}{l}79.8 \\
(6.64 \uparrow)\end{array}$ & $\begin{array}{l}69.4 \\
(9.65 \uparrow)\end{array}$ & 74.82 \\
\hline $\mathrm{T} 7$ & $\begin{array}{l}89.9 \\
(17.79 \uparrow)\end{array}$ & $\begin{array}{l}81.2 \\
(23.27 \uparrow)\end{array}$ & $\begin{array}{l}87.2 \\
(14.56 \uparrow)\end{array}$ & $\begin{array}{l}76.9 \\
(18.46 \uparrow)\end{array}$ & 83.80 \\
\hline Mean & 85.74 & 75.05 & 82.80 & 72.07 & \\
\hline $\begin{array}{l}\text { S.E } \pm \\
\text { CD at } 5 \%\end{array}$ & $\begin{array}{l}2.80 \\
V=0.807\end{array}$ & $\begin{array}{l}3.24 \\
T=1.068\end{array}$ & $\begin{array}{l}1.90 \\
V \times T=2.1\end{array}$ & 2.07 & \\
\hline $\begin{array}{l}\text { CD at } 5 \% \\
\text { CV\% }\end{array}$ & $\begin{array}{l}V=0.807 \\
1.65\end{array}$ & $\mathrm{~T}=1.068$ & $V \times T=2.1$ & & \\
\hline
\end{tabular}

Percentage decrease over control is represented by $\downarrow$ and percentage increase over drought is represented by $\uparrow$

maximum electrolyte evasion was recorded in PBW660 and PBW658 under water deficit stress induced by polyethylene glycol. Maximum percentage decrease in membrane stability was $27.04 \%$ in PBW660 and least in WH1105 (10.13\%). Similar significant reduction $(p<0.05)$ was recorded in membrane stability index in response to water stress (Aldesuquy and Ghanem, 2015). Sapre and Vakharia (2017) also recorded that PEG-6000 induced water deficit significantly decreased the membrane stability index. Exogenously applied kinetin provided stability to cell membranes and significantly reduced the leakage of

Table 2: Effect of different concentrations of kinetin (10,20 and $40 \mathrm{ppm}$ ) and benzyl adenine (25 and $50 \mathrm{ppm}$ ) on Triphenyltetrazolium chloride test at 7 DAS in wheat under PEG induced drought stress

\begin{tabular}{|c|c|c|c|c|c|}
\hline \multirow{2}{*}{$\begin{array}{l}\text { Treatments } \\
\text { Genotypes }\end{array}$} & \multicolumn{5}{|c|}{ Cell viability (\%) } \\
\hline & HD2967 & PBW660 & WH1105 & PBW658 & Mean \\
\hline $\mathrm{T} 1$ & 84.0 & 79 & 84 & 79 & 81.50 \\
\hline \multirow[t]{2}{*}{ T2 } & 62.0 & 59 & 66 & 56 & 60.75 \\
\hline & $(26.19 \downarrow)$ & $(25.31 \downarrow)$ & $(21.42 \downarrow)$ & $(29.11 \downarrow)$ & \\
\hline \multirow[t]{2}{*}{ T3 } & 70 & 66 & 72 & 63 & 67.75 \\
\hline & $(11.42 \uparrow)$ & $(10.60 \uparrow)$ & $(8.33 \uparrow)$ & $(11.11 \uparrow)$ & \\
\hline \multirow[t]{2}{*}{$\mathrm{T} 4$} & 76 & 75 & 81 & 69 & 75.25 \\
\hline & $(18.42 \uparrow)$ & $(21.33 \uparrow)$ & $(18.51 \uparrow)$ & $(18.84 \uparrow)$ & \\
\hline \multirow[t]{2}{*}{ T5 } & 88 & 81 & 88 & 77 & 83.5 \\
\hline & $(29.54 \uparrow)$ & $(27.16 \uparrow)$ & $(25.00 \uparrow)$ & $(27.27 \uparrow)$ & \\
\hline \multirow[t]{2}{*}{ T6 } & 73 & 73 & 77 & 70 & 73.25 \\
\hline & $(15.06 \uparrow)$ & $(19.17 \uparrow)$ & $(14.28 \uparrow)$ & $(20.00 \uparrow)$ & \\
\hline \multirow[t]{2}{*}{$\mathrm{T} 7$} & 86 & 80 & 85 & 74 & 81.25 \\
\hline & $(27.90 \uparrow)$ & $(26.25 \uparrow)$ & $(22.35 \uparrow)$ & $(24.32 \uparrow)$ & \\
\hline Mean & 77.00 & 73.28 & 79.00 & 69.71 & \\
\hline S.E & 3.59 & 3.07 & 2.96 & 3.05 & \\
\hline CD at $5 \%$ & $V=1.611$ & $\mathrm{~T}=2.132$ & $V \times T=N S$ & & \\
\hline CV \% & 3.48 & & & & \\
\hline
\end{tabular}

Percentage decrease over control is represented by $\downarrow$ and percentage increase over drought is represented by $\uparrow$ 


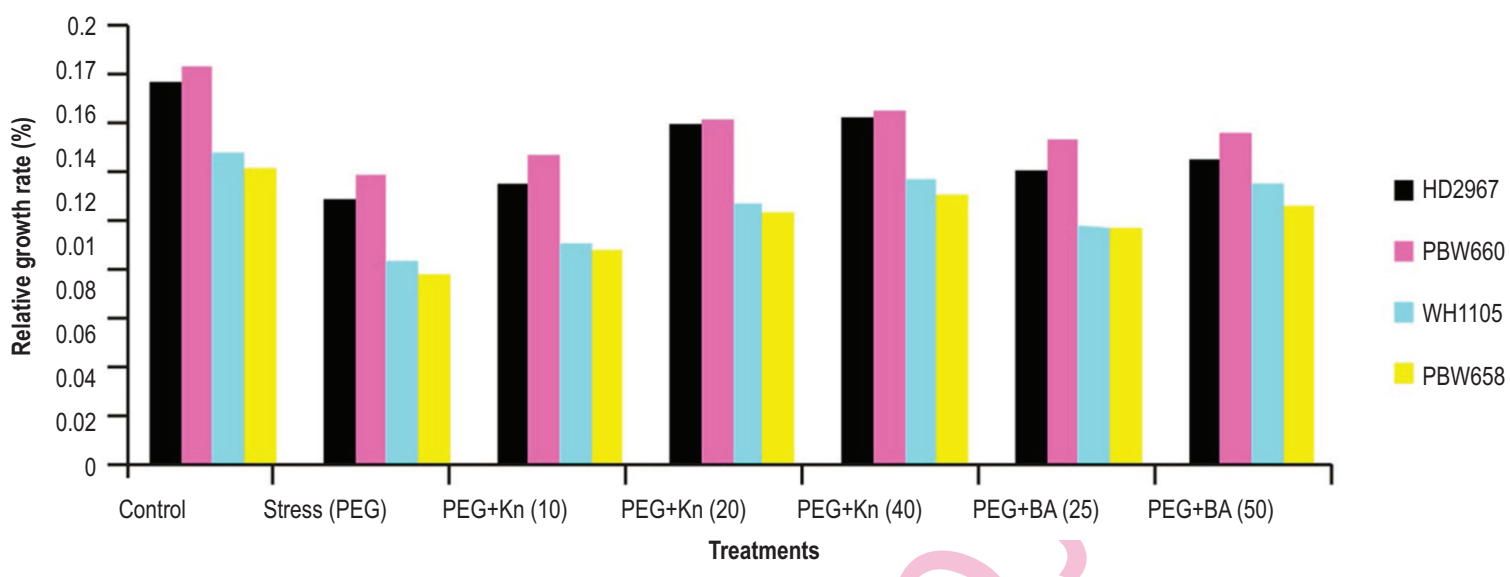

Fig. 1 : Effect of different concentrations of $\mathrm{Kn}(10,20$ and $40 \mathrm{ppm})$ and $\mathrm{BA}(25$ and $50 \mathrm{ppm})$ on relative growth rate (RGR) in wheat (a) HD2967, (b) PBW660, (c) WH1105 and (d) PBW658 under PEG induced drought stress. Varieties $(\mathrm{V})=0.002$, Treatments $(\mathrm{T})=0.003$, and $\mathrm{V} \times \mathrm{T}=0.006, \mathrm{CV}=3.16 \%$.

electrolytes in all studied genotypes. With kinetin @ 10 ppm HD2967 followed by WH1105 had higher stability of cell membranes, and PBW660 had minimum cell membrane stability. The maximum membrane stability over drought was recorded in HD2967 (9.76\%) followed by PBW660 (9.57\%) and slightest was recorded in $\mathrm{WH} 1105$ (7.91\%). At higher kinetin (20 ppm), all genotypes had significantly more membrane stability in contrast to low kinetin concentration, genotype HD2967 and WH1105 had more membrane stability. While HD2967 and WH1105 had high membrane stability and percentage increase was recorded more in PBW660 (25.47\%) and less in WH1105 (16.94\%). With Kinetin treatment @ 40 ppm. Exogenous benzyl adenine application significantly improved the stability of cell membranes. HD2967 and WH1105 had identical and higher membrane stability at benzyl adenine @ 25 ppm when compared with other studied genotypes. Benzyl adenine @ 50 ppm had more noteworthy impact membrane stability maintenance in all genotypes, higher percentage increase was recorded in PBW660 (23.27\%), while minimum was in observed WH1105 (14.56\%). Drought stress damages the selective permeability of plasma membrane and the cell cannot maintain its internal composition Barnabas et al. (2007). The damage caused by drought affects plant growth and development (Baiji, 2002). Duncan and Widholm (2004) reported that damaged cells loses their viability as revealed by TTC test. In this study, TTC test of all selected genotypes revealed high cell viability under controlled conditions and it decreased in polyethylene glycol treated seedlings (Table 2). HD2967 and WH1105 had comparable and more cell viability as compared to other genotypes under controlled conditions.

Polyethylene glycol reduced the viability significantly with more pronounced effect on PBW658. WH1105 maintained high cellular viability as compared to other genotypes even under drought stress. Maximum percentage decrease over control was

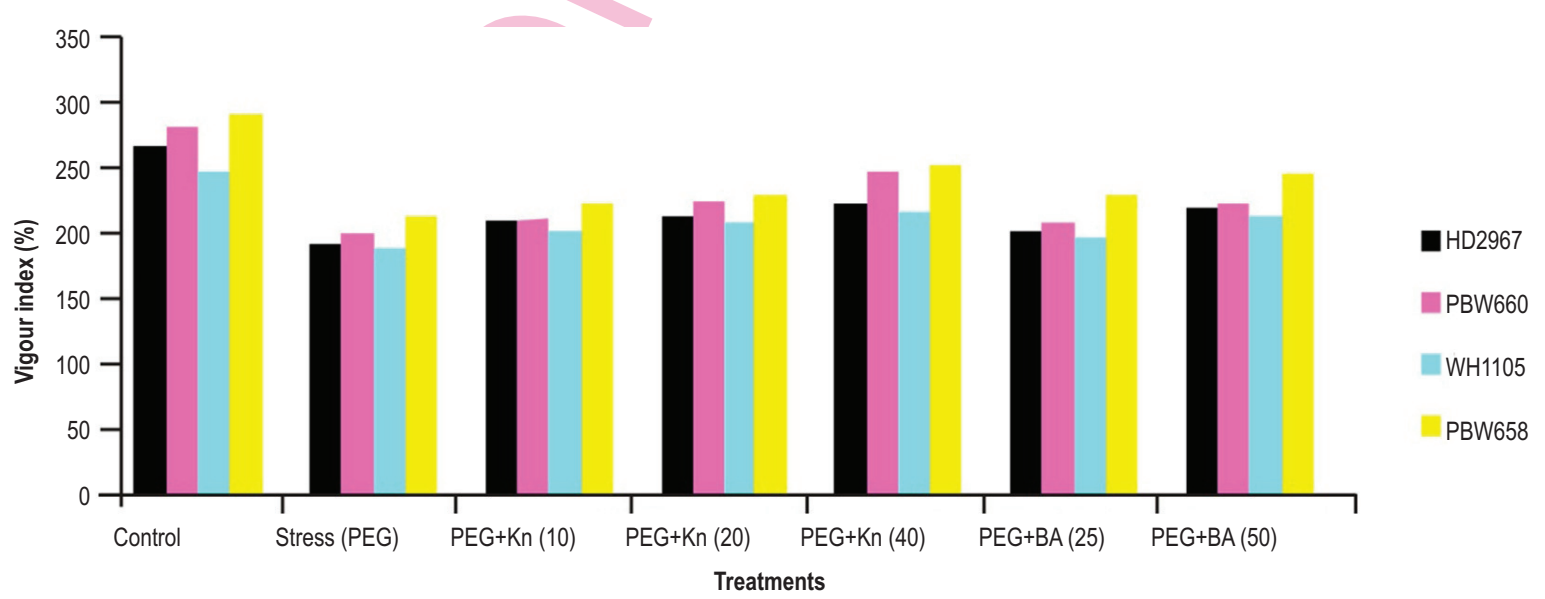

Fig. 2 : Effect of different concentrations of $\mathrm{Kn}$ (10, 20 and 40 ppm) and BA (25 and 50 ppm) on vigour index (VI) in wheat (a) HD2967, (b) PBW660, (c) WH1105 and (d) PBW658 under PEG induced drought stress. Varieties $(V)=1.309$, Treatments $(T)=1.732$, and $V \times T=3.464, C V=0.91 \%$. 
recorded in PBW658 (29.11\%) followed by HD2967 (26.19\%). Merewitz et al. (2010) observed that drought stress led to decrease in viability of roots. Foliar kinetin application increased the cell viability of all genotypes significantly. WH1105 attained the maximum cell viability and PBW658 had least at lower concentration (10 ppm) of kinetin. Percentage increase was recorded more in HD2967 (11.42\%) followed by PBW658 $(11.11 \%)$ and lesser was recorded in WH1105 (8.33\%). Higher concentration of kinetin ( $40 \mathrm{ppm}$ ) further protected the cells from polyethylene glycol induced damage and increased the cellular viability significantly, though HD2967 and WH1105 had higher cell viability when compared with other genotypes. Foliar application of benzyl adenine increased the cell viability of all genotypes significantly. WH1105 followed by HD2967 and PBW660 maintained high cellular viability while PBW658 least. At 50 ppm of benzyl adnine maximum percentage increase was recorded in HD2967 (27.90\%) while lesser was observed in WH1105 (22.35\%). Earlier, it was observed that the increase in exogenous cytokinin concentration increased the cell viability under drought stress (Xu et al., 2016) probably by cytokinin-enhanced ROS scavenging through antioxidant accumulation and activation of antioxidant enzymes.

The relative growth rate of wheat genotypes decreased under PEG induced drought stress as compared to control conditions (Fig. 1). The maximum decrease was observed in genotype PBW658; on the other hand genotype PBW660 followed by HD2967 possessed maximum RGR even under PEG induced drought stress. Datta et al. (2011) reported that relative growth rate in wheat genotypes declined progressively under stress conditions. Foliar application of kinetin increased the relative growth rate of genotypes significantly and reduced the unfriendly impact of PEG initiated drought stress. With the use of Kinetin @ 10 ppm, the genotype PBW660 had more relative growth rate. Kinetin @ 20 ppm further increased the relative growth rate of genotypes. The genotype PBW660 followed by HD2967 had more percentage increase in relative growth rate with application of kinetin @ 20 ppm. The higher kinetin application (Kn@ @ 40 ppm) indicated higher estimation of relative growth rate in all genotypes. The most extreme RGR was recorded in PBW660 followed by HD2967 with the use of kinetin@40ppm.

In this manner, higher concentration of kinetin (40 ppm) had more noteworthy impact on relative growth rate of genotypes as compared to lower kinetin concentrations tested. Earlier, priming with kinetin was found effective in increasing germination rate and early seedling growth in both salt tolerant and intolerant wheat plants (Iqbal et al., 2006). Both kinetin and benzyl adenine treatments reduced the unfavorable impact of PEG induced drought stress significantly. Foliar application of benzyl adenine increased the relative growth rate of all genotypes significantly. With benzyl adenine @ 25 ppm, genotype PBW660 followed by HD2967 had more relative growth rate while PBW658 had the least relative growth rate as compared to other genotypes. Application of benzyl adenine @ 50 ppm further increased the relative growth rate of all genotypes. With this application, the genotype PBW660 acquired the highest relative growth rate as compared to other genotypes, followed by HD2967.

As the vigour of the crop depends on the percentage germination and length of epicotyl, polyethylene glycol stimulated water deficit diminished the vigour of all genotypes studied in present study (Fig. 2). The most significant reduction over the control was seen in PBW660, followed by HD2967. Almaghrabi (2012) reported that PEG concentrations diminished the daily mean germination, index of germination and mean germination time in wheat genotypes. Kinetin application increased the vigour index of all the genotypes significantly under water deficit conditions. Kinetin application @10 ppm significantly ameliorated the negative effect of drought caused by polylethylene glycol and maximum vigour index was recorded in PBW658 followed by PBW660. On the other hand, maximum percentage increase was found in HD2967 followed by WH1105. Kinetin @ 20 ppm, showed significant increase in vigour index in all genotypes. Benzyl adenine additionally improved the negative impact of water deficit in the present study. With benzyl adenine @ 25 ppm, The most significant vigour index was recorded in genotype PBW658 followed by PBW660. Benzyl adenine @ 50 ppm, there was further increase in vigour of all genotypes. Prior, benzyl adenine pre-treatment could beat the negative impact of salt stress on rate germination, radical stretching and fresh weight in barley (Cavusoglu et al., 2008).

Thus, the present findings demonstrated that exogenous application of cytokinins to wheat genotypes viz. PBW660, HD2967, WH1105 and PBW658 has considerable potential for maintenance of membrane stability in order to maintain the cell viability, vigour index and relative growth of wheat seedlings growing under drought stress conditions.

\section{Acknowledgment}

First author is highly thankful to Inspire Fellowship funded by Department of Science and Technology, New Delhi, India, for providing financial support for research work.

\section{References}

Abdul-Baki, A. A. and J. Anderson: Vigour determination in soybean seed by multiple criteria. Crop. Sci., 13, 630-632 (1973).

Aldesuquy, $\mathrm{H}$. and $\mathrm{H}$. Ghanem: Exogenous salicylic acid and trehalose ameliorate short term drought stress in wheat cultivars by upregulating membrane characteristics and antioxidant defense system. J. Hortic. Sci., 2, 2 (2015).

Almaghrabi, O. A.: Impact of drought stress on germination and seedling growth parameters of some wheat cultivars. Life. Sci. J., 9, 590598 (2012).

Bajji, M., J.M. Kinet and S. Lutts: The use of the electrolyte leakage method for assessing cell membrane stability as a water stress tolerance test in durum wheat. Plant Growth Regul., 36, 61-70 (2002).

Barnabás, B., K. Jäger and A. Fehér : The effect of drought and heat stress on reproductive processes in cereals. Plant Cell Environ., 
31, 11-38 (2007).

Buchanan, B. B., W. Gruissem and R.L. Jones : Biochemistry and Molecular Biology of Plants. Amer. Soc. Plant. Physiol. Rockville (2000).

Cavusoglu, K., S. Kilic and K. Kabar: Effects of some plant growth regulators on leaf anatomy of radish seedlings grown under saline conditions. J. Appl. Biol. Sci., 2, 47-50 (2008).

Cochran, W., G. and G.M. Cox : Experimental Designs. John Wiley and Sons Ltd., England (1967).

Datta, J.K., T. Mondal, A. Banerjee and N.K. Mondal: Assessment of drought tolerance of selected wheat cultivars under laboratory condition. J. Agri. Technol., 7, 383-393 (2011).

Duncan, R. D. and J.M. Widholm: Osmotic induced stimulation of the reduction of the viability dye 2, 3, 5 triphenlytetrazolium chloride by maize roots and callus cultures. J. Plant Physiol., 161, 397-403 (2004)

FAO.: World Food and Agriculture. Statistical Yearbook. Food and Agriculture Organization of the United States, Rome (2013).

FAO. World Food and Agriculture. Statistical Yearbook. Food and Agriculture Organization of the United States, Rome (2015).

Gardener, F. P., R. B. Pearce and R. L. Mitchell: Physiology of crop plants. Lowa State University Press. pp. 187-208 (1985).

Iqbal, M., M. Ashraf, A. Jamil and S. Ur-Rehman: Does seed priming induce changes in the levels of some endogenous plant hormones in hexaploid wheat plants under salt stress? J. Integ. Plant. Biol., 48, 81-189 (2006)

Kulkarni, M. and U. Deshpande: In-vitro screening oftomato genotypes for drought resistance using polyethylene glycol. Afr. J. Biotechnol., 6, 691-696 (2007)

Merewitz, E.B., T. Gianfagna and B. Huang: Effects of SAG12-ipt and HSP18.2-ipt expression on cytokinin production, root growth and leaf senescence in creeping bentgrass exposed to drought stress. J. Am. Soc. Hortic. Sci., 135, 230-239 (2010).

Okamoto, M., K. Tatematsu and A. Matsui: Genome-wide analysis of endogenous abscisic acid-mediated transcription in dry and imbibed seeds of Arabidopsis using tiling arrays. The Plant J., 62 , 39-51 (2010).

Rauf, M., M. Munir, M. Ul-Hassan, M. Ahmed and M. Afzai: Performance of wheat genotypes under osmotic stress at germination and early seedling growth stage. Afr. J. Biotechnol., 8, 971-975 (2007).

Sapre, S. S. and D. N. Vakharia: Silicon induced physiological and biochemical changes under polyethylene glycine-6000 water deficit stress in wheat seedlings. J. Environ. Biol., 38, 313-319 (2017).

Shanahan, J. F., I.B. Edwards, J.S. Quick and Fenwick : Membrane thermostability and heat tolerance of spring wheat. Crop. Sci., 30, 247-251 (1990).

Tardieu, F.,P. Kesavan, J. Bocianowski, M. Bilal, Y. Sohrabi, T. Dai, Q. Qanmber, A. Latif, J. Ashraf and U. Farhan: Any trait or trait related allele can confer drought tolerance: Just design the right drought scenario. J. Exp. Bot., 63, 25-31 (2012).

Towill, L.E. and P. Mazur : Studies on the reduction of 2,3,5-triphenyl tetrazolium chloride assay for plant tissue culture. Can. J. Bot., 53, 1097-1102(1974).

Vadez, V., J. Kholova, S. Choudhary, P. Zindy, M. Terrier, L. Krishnamurth, P.R. Kumar and N.C. Turner: Whole plant response to drought under climate change. In: Crop adaptation to climate change Chichester-Wiley-Blackwell (2011).

Vadez, V., J.D. Berger, T. Warkentin, S. Asseng, P. Ratnakumar, K.P.C. Rao, P.M. Gaur, N. Munier-Jolain, A. Larmure, A.S. Voisin, H.C. Sharma, S. Pande, M. Sharma, L. Krishnamurthy and M.A. Zaman : Adaptation of grain legumes to climate change: A review. Agron. Sustain. Dev., 32, 31-44 (2012).

Wang, X., M-M.Zhang,Y-J.Wang, Y-T.Gao, R. Li, R. G-F. Wang, W-Q.Li, W-T.Liu and K.M. Chen : The plasma membrane NADPH oxidase OsRbohA plays a crucial role in developmental regulation anddrought-stress response in rice. Physiol. Plant, 156, 421-443 (2016).

Xu, Y., B. Patrick, Z. Xunzhong and H. Bingru : Enhancing cytokinin synthesis by overexpressing ipt alleviated drought inhibition of root growth through activating ROS-scavenging systems in Agrostis stolonifera J. Exp. Bot., 67, 1979-1992 (2016)

Yang, J., J. Zhang, Z. Wang, Q. Zhu and L. Liu:Abscisic acid and cytokinins in the root exudates and leaves and their relationship to senescence and remobilization of carbon reserves in rice subjected to water stress during grain filling. Planta, 215, 645-652 (2002) 